\title{
Alveolar ridge expansion by implants with osteodistractive function: A clinical report
}

\author{
Alberto Maltagliati, Francesca Angiero, Franco Ferrante, Sergio Blasi and Andrea Ottonello* \\ Department of Integrated Diagnostic and Surgical Sciences, Università degli studi di Genova, Genova, Italia
}

\begin{abstract}
The edentulous areas of the jaws, especially suffering from bone atrophy, still represent a prosthetic challenge for dental implants placement. For this reason, distraction osteogenesis is gaining more ground in dentistry, particularly in dental implants treatment, offering the possibility to restore and rehabilitate edentulous ridges with insufficient dimensions. The aim of the present report is to introduce the employment of dental implants with horizontal osteodistractive function to restore the dimensions of resorbed alveolar ridges without resorting to osteotomies or bone distractors. With such technique, a total of 25 patients have been treated, with edentulous premolar and/or molar regions receiving a total of 67 implants. Results and controls at 3, 6, 12 and 24 months are encouraging and show optimum implants osteointegration. The horizontal expansion technique that employs the same implants as a tool for distraction osteogenesis helps obtaining horizontal alveolar ridge expansion with a single surgical appointment which reduces significantly the risk of fracture and fenestration.
\end{abstract}

\section{Introduction}

Osteointegrated implants are considered to date a solid prosthetic replacement for missing teeth, now with a history of decades of predictability [1,2]. It has been demonstrated that the functional load of the implants reduces bone resorption [3]. On the other hand, there are minimum dimensional requirements for horizontal width and vertical height of the alveolar ridge necessary for placement of a successful dental implant $[4,5]$. In this latter regard, a protocol for a surgical technique that guarantees a reliable and optimal rehabilitation by dental implants prosthetics is yet to be developed. Despite the continual optimization of the implant materials [6], their surface characteristics and the prosthetics they receive, challenges such as technical, functional and esthetic limitations still exist [7-10]. Consistent progress has been reported in the literature regarding the pre-implantation surgical techniques, often necessary, and regarding attempts to improve the initial anatomy of the edentulous ridge, usually suffering from atrophy and inadequacy to receive a dental implant [11]. The evolution of surgical techniques and the development of osteotomy prophylometric implant morphology have extended the indications of dental implants employment even in cases that were completely contraindicated from implants therapy in the past or the ones that were subject to several guided bone regeneration (GBR) procedures before implants placement [12]. In fact, it has been confirmed that the implants should be inserted according to a precise prosthetic stent even in the absence of adequate bone support or with sub-ideal 3D skeletal relationships. This modern approach by prosthetic dental implants assumes not only the necessity of having adequate bone width obtained by distraction, reconstruction or regeneration techniques but also to surgically adjust the undesirable bone morphologic changes related to resorption following the loss of teeth $[13,14]$. Accordingly, it is now feasible for a dental implant team to plan and implement adequate ridge volume and morphology for optimum implant insertion [15].

Coined since decades, distraction osteogenesis is a technique that targets the entire or partial elongation of a bone segment via surgical separation while leaving intact all associated soft tissue [16]. Such technique has found wide application in maxillofacial surgery and dental implants to restore edentulous alveolar ridges of inadequate horizontal and vertical dimensions [17-20].

The aim of this report is hence to introduce the employment of dental implants with horizontal osteodistractive function to restore the dimensions of resorbed edentulous alveolar ridges.

\section{Materials and methods}

25 patients aged between 46 and 71 years (mean age 57.4) - 14 females and 11 males - participated in our study; each one had previously signed an informed consent. We have excluded from the study patients who had denied consent, patients with poor oral hygiene having full mouth Plaque Score (FMPS) $\geq 20 \%$ before surgery, patients with compromised periodontium or local soft tissue infections, patients with psychiatric illnesses and pregnant women. All patients were edentulous in their premolar and/or molars regions with ridge width between 3 and $5 \mathrm{~mm}$ in at least one of the designated sites for implant placement (Figure 1). All cases received a total of 67 implants with bone distraction function in the coronal area of the alveolar ridge without crestal opening or any kind of osteotomies (Figure 2). When necessary, in cases with ridge width less than $3 \mathrm{~mm}$ on the vestibular cortex ( 9 out of 25), bone augmentation took place by OsteoBiol Putty ${ }^{\mathbb{R}}$ bone grafting material (Figure 3).

In every patient the alveolar crest has been exposed by a horizontal full thickness crestal incision. An initial osteotomy of diameter $1.2 \mathrm{~mm}$

Correspondence to: Andrea Ottonello, Department of Integrated Diagnostic and Surgical Sciences, Università degli studi di Genova, L.go Rosanna Benzi 8 , 16132 Genova, Italia,Tel: +393384793547, +390103537433, Fax: +39010532524, E-mail: andrea.ottonello@unige.it

Received: November 10, 2016; Accepted: November 23, 2016; Published: November 26, 2016 


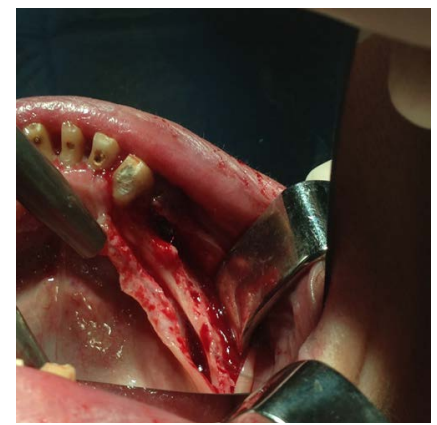

Figure 1. Bone crest exposure after full-thickness flap elevation.

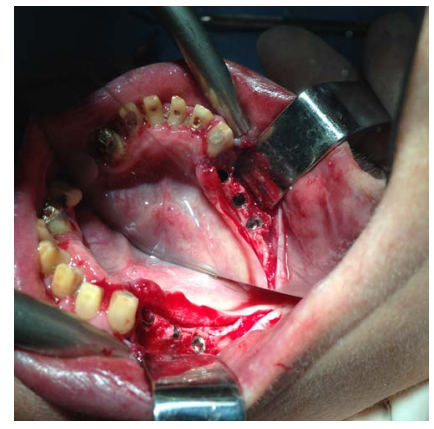

Figure 2. Implants insertion.

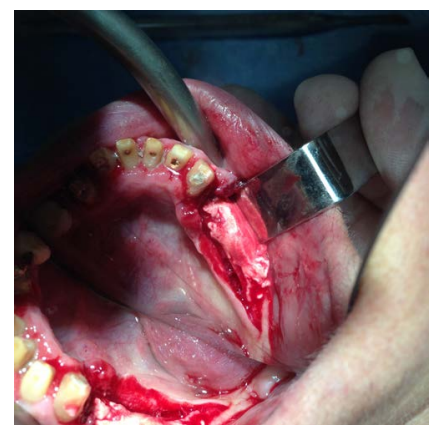

Figure 3. Bone regeneration with Osteobiol Putty.

was drilled and enlarged to $2.0 \mathrm{~mm}$ then to $2.5-3.0 \mathrm{~mm}$ to receive the dental implant.

We put implants Tekka In-Kone ${ }^{\circledR}$ Universal switch platform of 10 and $11.5 \mathrm{~mm}$, characterized by a $2.5 \mathrm{~mm}$ collar and a conical spiral with cylindrical profile and a self-tapping apex. Therefore, ridge extension has been performed without osteotomy or bone distraction.

All implants have been inserted with a protocol consisting of 3-step osteotomy drilling without using neck drills and screwed intermittently every 5 turns to recuperate the elastic memory of the cortical bone. The implants have been inserted at $1.5 / 2.5 \mathrm{~mm}$ beyond the alveolar crest. Before closing by full-thickness suture with horizontal mattress technique, we proceeded with full flap passivation, in order to guarantee the best graft vascularization. Then all incisions have been closed and the actual functional implant load took place 3 months post-operative - 4 months in cases treated with regeneration (Figures 4 and 5). All cases have been monitored and checked up at 3, 6, 12 and 24 months.

\section{Results}

All implants have been osteointegrated at the last check at 2 months, as confirmed by probing and radiographs. We report a selected case of a 62 y.o. female patient, treated in the edentulous area 4.4-4.5-4.6 (Figure 6), to which all pictures are referred.

The use of dental implants with such technique guarantees the ridge expansion without additional osteotomies or distractors: the implant itself is the necessary and sufficient tool to obtain the sought bone distraction by a series of simple steps highly predictable and repeatable. The gradual helices in the implants allow the operator to reduce the time between surgeries and after the final surgery waiting for the eventual complete regeneration of the implants sites.

The switch platform protocol allows the insertion below the bone crest even more that $2 \mathrm{~mm}$ with the necessity of some bone recontouring which is regarded as a natural protective mode for the neck of the implant especially since when it is not preceded with the insertion of transmucosal collar.

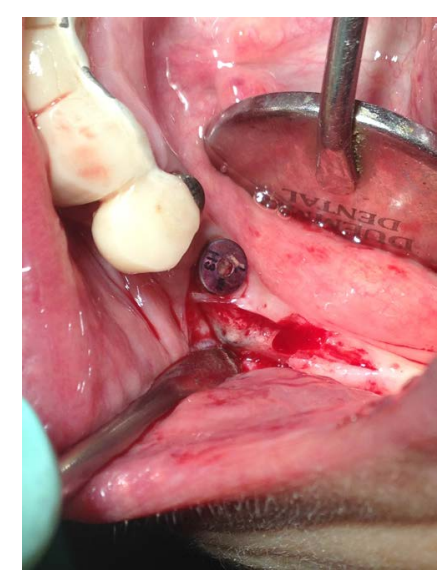

Figure 4. Re-opening of the site at 4 months.

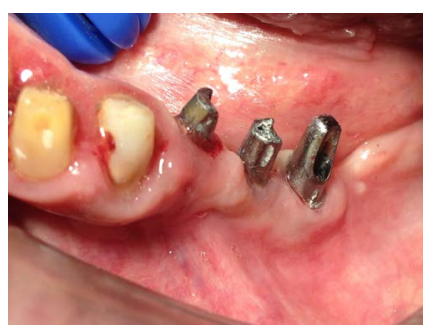

Figure 5. Abutments.

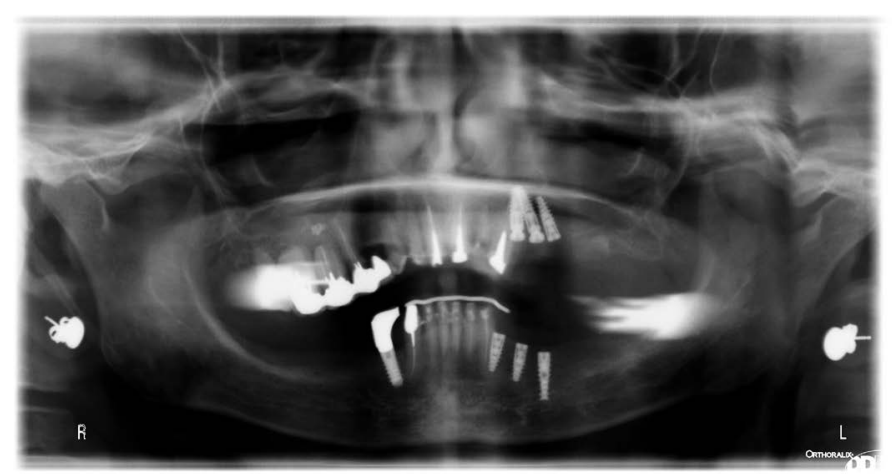

Figure 6. Panoramic radiograph of a case of a 62 y.o. female patient, treated in the edentulous area 4.4-4.5-4.6. 


\section{Conclusion}

Today dental implants combined to pre-insertion surgical techniques such as ridge distraction present an optimal modality to restore the lost dentition in patients suffering from alveolar atrophy. To date, the available literature even from the broader field of orthopedic and maxillofacial surgery, has demonstrated that through distraction osteogenesis techniques it is possible to give way to neo-formation of bone tissue that have similar characteristics of the original bone, hence favoring the successful insertion and integration of dental implants [21-23].

The horizontal distraction technique, matter of this paper, that employs the very same implants as a distraction tool, allows the augmentation of the alveolar ridge horizontal dimensions with one single surgical step, hence reducing to the minimum the biological and financial cost for the patient. In most of the cases with mandibular atrophy, mainly bone of type D1 or D2 are encountered complicating any surgical approach [24] the use of implants with bone distraction ability reduces significantly fracture and fenestration risks, which are undesirable but frequent events occurring with traditional surgical techniques. Besides, bone distraction implants increase the comfort of the patient who otherwise would have to face several traumatic surgeries.

Finally, the prosthetic connection with switch platform, when permitting the insertion of the implant $2 \mathrm{~mm}$ below the alveolar crest, prevents peri-implant conical resorption which favours reliable long term reproducibility of such technique.

\section{Conflicts of interest}

The authors declare that they have no conflict of interest.

\section{Financial disclosure}

The authors declare that this work was not supported by any funding source.

\section{References}

1. Albrektsson T, Dahl E, Enbom L, Engevall S, Engquist B, et al. (1988) Osseointegrated oral implants. A Swedish multicenter study of 8139 consecutively inserted Nobelpharma implants. J Periodontol 59: 287-96. [Crossref]

2. Tonetti M, Palmer R, Artzi Z, Cairo F, Donati M, et al. (2012) Clinical research in implant dentistry: study design, reporting and outcome measurements: consensus report of Working Group 2 of the VIII European Workshop on Periodontology. J Clin Periodontol 39: 73-80. [Crossref]

3. Reddy MS, Geurs NC, Wang IC, Liu PR, Hsu YT, et al. (2002) Mandibular growth following implant restoration: does Wolff's law apply to residual ridge resorption? Int J Periodontics Restorative Dent 22: 315-321. [Crossref]

4. Hahn J (1999) Clinical uses of osteotomes. J Oral Implantol 25: 23-29. [Crossref]

5. Krekmanov L (1995) A modified method of simultaneous bone grafting and placement of endosseous implants in the severely atrophic maxilla. Int J Oral Maxillofac Implants 10: 682-688. [Crossref]

6. Maltagliati A, Sergiampietri D, Angiero F, Ottonello A (2016) The role of the zirconium collar in reducing peri-implant bacterial proliferation. Il Dentista Moderno 11: 58-63.

7. Giannobile WV, Lang NP2 (2016) Are Dental Implants a Panacea or Should We Better Strive to Save Teeth? J Dent Res 95: 5-6. [Crossref]

8. Schiroli G, Angiero F, Zangerl A, Benedicenti S, Ferrante F, et al. (2016) Accuracy of a flapless protocol for computer-guided zygomatic implant placement in human cadavers: expectations and reality. Int J Med Robot 12: 102-108. [Crossref]

9. Naert I, Koutsikakis G, Duyck J, Quirynen M, Jacobs R, et al. (2002) Biologic outcome of implant-supported restorations in the treatment of partial edentulism. part I: A longitudinal clinical evaluation. Clin Oral Implants Res 13: 381-389. [Crossref]

10. Romeo E, Chiapasco M, Ghisolfi M, Vogel G (2002) Long-term clinical effectiveness of oral implants in the treatment of partial edentulism. Seven-year life table analysis of a prospective study with ITI dental implants system used for single-tooth restorations. Clin Oral Implants Res 13: 133-143. [Crossref]

11. McAllister BS, Haghighat K (2007) Bone augmentation techniques. J Periodontol 78: 377-396. [Crossref]

12. Buser D, Chappuis V, Kuchler U, Bornstein MM, Wittneben JG, et al. (2013) Longterm stability of early implant placement with contour augmentation. J Dent Res 92 : 176S-82S. [Crossref]

13. de Wijs FL, Cune MS (1997) Immediate labial contour restoration for improved esthetics: A radiographic study on bone splitting in anterior single-tooth replacement. Int J Oral Maxillofac Implants 12: 686-96. [Crossref]

14. Gaggl A, Rainer H, Chiari FM (2005) Horizontal distraction of the anterior maxilla in combination with bilateral sinuslift operation--preliminary report. Int J Oral Maxillofac Surg 34: 37-44. [Crossref]

15. Bassi F, Carr AB, Chang TL, Estafanous EW, Garrett NR, et al. (2013) Functional outcomes for clinical evaluation of implant restorations. Int J Prosthodont 26: 411-418. [Crossref]

16. Ilizarov GA (1989) The tension-stress effect on the genesis and growth of tissues. Part I. The influence of stability of fixation and soft-tissue preservation. Clin Orthop Relat Res 249-281. [Crossref]

17. Simion M, Baldoni M, Zaffe D (1992) Jawbone enlargement using immediate implant placement associated with a split-crest technique and guided tissue regeneration. Int $J$ Periodontics Restorative Dent 12: 462-473. [Crossref]

18. Cruz M, Reis CC, Mattos FF (2001) Implant-induced expansion of atrophic ridges for the placement of implants. J Prosthet Dent 85: 377-381. [Crossref]

19. Ferrigno N, Laureti M (2005) Surgical advantages with ITI TE implants placement in conjunction with split crest technique. 18-month results of an ongoing prospective study. Clin Oral Implants Res 16: 147-155. [Crossref]

20. Yalcin S, Ordulu M, Emes Y, Gur H, Aktas I, et al. (2006) Alveolar distraction osteogenesis before placement of dental implants. Implant Dent 15: 48-52. [Crossref]

21. Rachmiel A, Srouji S, Peled M (2001) Alveolar ridge augmentation by distraction osteogenesis. Int J Oral Maxillofac Surg 30: 510-517. [Crossref]

22. Marx RE, Shellenberger T, Wimsatt J, Correa P (2002) Severely resorbed mandible: predictable reconstruction with soft tissue matrix expansion (tent pole) grafts. $J$ Oral Maxillofac Surg 60: 878-888. [Crossref]

23. von Arx T, Buser D (2006) Horizontal ridge augmentation using autogenous block grafts and the guided bone regeneration technique with collagen membranes: a clinical study with 42 patients. Clin Oral Implants Res 17: 359-366. [Crossref]

24. Juodzbalys G, Raustia AM (2004) Accuracy of clinical and radiological classification of the jawbone anatomy for implantation--a survey of 374 patients. J Oral Implantol 30: 30-39. [Crossref]

Copyright: (C2016 Maltagliati A. This is an open-access article distributed under the terms of the Creative Commons Attribution License, which permits unrestricted use, distribution, and reproduction in any medium, provided the original author and source are credited. 